\title{
CAPACITAÇÃO DE CRIANÇAS COM DIFICULDADES INTELECTUAIS PARA BOAS PRÁTICAS ALIMENTARES
}

\author{
M. A. BONÉ ${ }^{1}$, J. BONITO ${ }^{2 *}$ e V. CALDEIRA ${ }^{3}$ \\ ${ }^{1}$ Agrupamento de Escolas de Monforte - Portugal \\ ${ }^{2}$ Universidade de Évora. CIDTFF da Universidade de Aveiro - Portugal \\ ${ }^{3}$ Escola Superior das Tecnologias da Saúde de Lisboa - Portugal \\ jbonito@uevora.pt
}

Artigo submetido em fevereiro/2015 e aceito em junho/2015

DOI: $10.15628 /$ holos.2015.2738

\section{RESUMO}

A obesidade é considerada pela Organização Mundial de Saúde uma epidemia do século XXI. Existe evidência científica suficientemente forte que associa as práticas alimentares à obesidade. Os estudos acerca dos hábitos alimentares entre a população com necessidades educativas especiais escasseiam, em Portugal. Este trabalho parte do pressuposto que a capacitação de pessoas com dificuldades intelectuais contribui favoravelmente para as suas escolhas alimentares. Desenvolveu-se com seis alunas institucionalizadas, do terceiro ciclo do ensino básico português, com dificuldades intelectuais, de um agrupamento de escolas do distrito de Portalegre, no ano letivo de 2013/2014 Fez-se avaliação antropométrica e observação não participante dos sujeitos, relativamente aos seus hábitos e às suas práticas alimentares, em ambiente escolar. A análise da informação permitiu elaborar um plano de capacitação para escolhas alimentares saudáveis, desenvolvido em função da especificidade de cada sujeito. Os resultados apontam para uma alteração nos comportamentos alimentares no período imediatamente decorrente à implementação do programa de capacitação.

PALAVRAS-CHAVE: alimentação saudável, dificuldades intelectuais, capacitação, educação para a saúde.

\section{CHILDREN EMPOWERMENT WITH INTELLECTUAL DIFFICULTIES FOR GOOD PRACTICE FOOD}

\begin{abstract}
Obesity is considered by the World Health Organization an epidemic of the XXI century. There is strong enough scientific evidence linking eating habits to obesity. Studies on dietary habits among the population with special educational needs are scarce in Portugal. This work assumes that the empowerment of people with intellectual disabilities contributes favorably to their food choices. It was developed with six cases of institutionalized students with intellectual disabilities, of the third cycle of basic education, at a group of schools
\end{abstract}

in the district of Portalegre (Portugal), in academic year $2013 / 2014$. There was anthropometric and nonparticipant observation of subjects, for their habits and their eating habits in the school environment. Information analysis allowed us to elaborate a training plan for healthy food choices, developed in the specific nature of each case. The results point to a change in feeding behavior in the period immediately due to the implementation of the training program.

KEYWORDS: healthy eating, intellectual difficulties, empowerment, health education. 


\section{INTRODUÇÃO}

\subsection{Contextualização histórica da Educação Especial}

No decorrer da história do ser humano, as sociedades edificaram estigmas e superstições envolvendo as pessoas com deficiência. A seleção biológica prossegue a seleção natural, postulada por Darwin. As práticas adotadas por diferentes povos, nomeadamente o espartano, que elimina à nascença crianças com malformações, o ateniense que as abandona nas montanhas, e o romano que as atira aos rios, são disso testemunho. Antagonicamente verificase, ainda, a adoração destes indivíduos por associação ao divino. Na Idade Média, surgem práticas exorcistas ao entender-se que estão possuídos por espíritos malévolos (BAUTISTA, 1997).

A Educação Especial (EE) inicia-se com a institucionalização de crianças com deficiência, acontecendo, entre o século XVII e o XIX, evoluções consideráveis. Destacados pensadores demonstram preocupação com os direitos dos indivíduos e com as estratégias facilitadoras de aprendizagens, mormentemente: Jean Jacques Rosseau (1712-1778), suíço, que advoga a filosofia social e educacional assim como os direitos humanos; Joahann Heinrich Pestalozzi (17461827), suíço, fundador de uma educação alicerçada na observação direta e participação ativa; Jacob Rodrigues Pereira (1715-1780), espanhol, criador de um alfabeto manual e que alerta para a possibilidade dos surdos lerem e falarem; e Jean Marc Itard (1774-1838), francês, que se celebriza pela educação de Victor de Aveyron (c. 1788-1828), criança selvagem, com recurso a estimulações sensoriais e sociais. No século XIX criam-se escolas especiais para cegos e surdos e, no final deste, é iniciado o atendimento a pessoas com Deficiência Mental (DM) (BAUTISTA, 1997).

A Declaração Mundial sobre Educação para Todos (UNESCO, 1990) demarca a rutura formal com a EE, reforçando-se este distanciamento com a Conferência Mundial sobre Necessidades Educativas Especiais (NEE) originadora da Declaração de Salamanca, no ano de 1994. Esta Declaração, assinada por 92 países, entre os quais Portugal e o Brasil, bem como por 25 organizações internacionais, define os princípios base da escola e educação inclusivas. Na atualidade, este documento de referência situa os direitos da criança e dos jovens com NEE no contexto mais amplo, aludindo à Convenção dos Direitos da Criança (1989), à Declaração Mundial sobre Educação para Todos (1990) e, também, às Normas das Nações Unidas sobre a Igualdade de Oportunidades para Pessoas com Deficiência (1993) (UNESCO, 1994).

A Carta do Luxemburgo (1996), que postula o princípio da não-discriminação, também mencionado no Tratado de Amesterdão (1997), o Enquadramento de Ação de Dakar (2000), que objetiva a Educação para Todos até 2015, e a Declaração de Madrid (2002), que anuncia o princípio de "não discriminação + ação positiva = inclusão social", são documentos que apoiam a implementação das ideias difundidas (apud SANCHES; TEODORO, 2006).

A Convenção dos Direitos da Criança (UNICEF, 1989), adotada pela Assembleia Geral nas Nações Unidas em 20 de novembro de 1989, define no seu artigo 10 que criança é todo o indivíduo com idade inferior a 18 anos, exceto se a lei nacional outorgar a maior idade mais prematuramente. Portugal ratificou esta Convenção em 21 de setembro de 1990, vigorando na 
ordem interna, nos termos do no 2 do artigo 8을 da Lei Constitucional no 1/2005, de 12 de agosto (sétima revisão constitucional).

O conceito de NEE, baseado em critérios pedagógicos, surge no sistema educativo português através do Decreto-Lei no 319/1991, de 23 de agosto. As escolas dispuseram, então, de um suporte legal para organizar o seu funcionamento no respeitante a estes alunos. Segundo Correia (1999), as NEE ajustam-se a crianças e a adolescentes que manifestam problemas sociais, físicos, intelectuais e emocionais, assim como as dificuldades de aprendizagem, resultantes de fatores orgânicos ou ambientais. O conceito refere-se a crianças que não conseguem acompanhar o currículo normal e que, consequentemente, necessitam que se proceda à realização de adaptações, mais ou menos generalizadas por forma a gerar-se um ambiente inclusivo. A Declaração de Salamanca (UNESCO, 1994) define o conceito de NEE com abrangência de crianças que revelam carências relacionadas com deficiências ou dificuldades escolares e, em função destas, apresentam NEE em determinado momento do seu processo de escolaridade, integrando crianças sobredotadas, crianças com deficiência, crianças que trabalham, crianças de populações nómadas, crianças de minoria linguística, étnica ou cultural e de grupos desfavorecidos ou marginais. A Declaração de Salamanca apresenta-se questionadora do sistema de ensino e dos seus intervenientes, visando uma resposta efetiva a todos os alunos com reflexos contributivos numa sociedade inclusiva (BÉNARD DA COSTA, 2005).

\subsection{Contexto inclusivo}

Inclusão é um conceito da atualidade. Não se restringe a crianças e a jovens com deficiência. Estende-se à totalidade de quantos frequentam a escola já que o fazem para realizar aprendizagens de forma participada, devendo o ensino adaptar-se às suas necessidades individuais, conforme a define a Declaração de Salamanca:

o princípio orientador deste Enquadramento da Ação consiste em afirmar que as escolas se devem ajustar a todas as crianças, independentemente das suas condições físicas, intelectuais, linguísticas ou outras. Neste conceito terão de se incluir crianças com deficiência ou sobredotados, crianças de rua ou crianças que trabalham, crianças de populações remotas ou nómadas, crianças de minorias linguísticas, étnicas ou culturais e crianças de áreas ou grupos desfavorecidos ou marginais. (UNESCO, 1994, p. 11)

O princípio da inclusão apela à escola para a atenção da criança na sua plenitude e não apenas como aluno respeitando os desenvolvimentos académico, sócio emocional e pessoal (CORREIA, 1999). Desta forma, deverá ser proporcionada à criança uma educação que aponte no sentido de maximizar o potencial individual.

Para Ainscow e Ferreira (2003), a inclusão é uma "proposta educativa que pretende consubstanciar a simultaneidade do tempo e do espaço pedagógicos para todas as crianças, por forma a concretizar os ideais de educação pública obrigatória: qualidade, eficiência, igualdade e equidade" (p. 59). Na perspetiva de Baptista (2011, p. 79), a inclusão objetiva singularmente cada indivíduo. $\mathrm{O}$ autor defende que a escola inclusiva é a que "combate as diferenças; favorece a igualdade de oportunidades; reconhece e satisfaz as necessidades dos alunos; garante um bom nível de educação; sensibiliza os alunos, pais e comunidade; utiliza recursos e cria novos métodos de aprendizagem; recorre a estratégias diversificadas; proporciona a integração na vida 
económica e social e não deixa nenhum aluno para trás". De acordo com Correia (2003), a EE e a inclusão, caminham num sentido comum visando assegurar os direitos fundamentais dos alunos com NEE e ainda como facilitadores das aprendizagens, onde se alicerçará a inserção na sociedade.

As escolas frequentemente deparam-se com questões como a diversidade étnica, cultural, comportamental, saúde, dificuldades de aprendizagem, deficiência, violência, entre outos. De acordo com Sanches e Teodoro (2006), falar de educação inclusiva é abordar um conjunto amplo de aprendizagens criativas e estimulantes, proporcionadas para o grupo e no grupo, objetivando a resposta adequada a todos os alunos respeitando-os na sua individualidade. Ainscow e Ferreira (2003) consideram a diferença uma mais-valia e a escola um lugar que proporciona interação de aprendizagens significativas a todos os seus alunos, alicerçada na cooperação e na diferenciação inclusiva. O autor postula que a inclusão envolve: a) processos de ampliação da participação de estudantes e de redução da sua exclusão de currículos, culturas e comunidades de escolas locais; b) reestruturação de culturas, políticas e práticas em meio escolar por forma a responder à diversidade; c) a presença, a participação e a realização de todos os estudantes vulneráveis a pressões exclusivas, não somente aqueles com NEE.

Nielsen (1999) considera a educação inclusiva com um papel centrado no professor para providenciar tarefas/atividades em que o aluno obtenha sucesso e desenvolva as suas potencialidades individuais num ambiente rico, estimulante, ativo e de experimentação. A escola inclusiva deve permitir que o aluno com NEE seja aceite e respeitado pela comunidade social da escola e interaja com os pares participando e inter-relacionando-se em todo o tipo de atividades (LIMA-RODRIGUES, 2007). A interação com os pares permite a identificação, reforço de competências, o equilíbrio pessoal e relacional facilitando o estabelecimento de novas aprendizagens. As escolas regulares constituem os meios mais competentes para lutar contra atitudes discriminatórias, criando comunidades abertas e solidárias, edificando uma sociedade inclusiva, logrando a educação para todos (LIMA-RODRIGUES, 2007). A EE auspicia, no tempo presente, a inclusão educativa e social, o ingresso e o sucesso educativos, a autonomia, a solidez emocional, a paridade de oportunidades, preparação para o prosseguimento dos estudos ou para a vida profissional e a evolução do meio escolar para o profissional, das crianças com NEE, nos termos do arto 1 으 do Decreto-Lei no 3/2008, de 7 de janeiro.

\section{ALIMENTAÇÃO E SAÚDE}

\subsection{Alimentação}

A alimentação constitui a necessidade primeira para o ser humano ao ser o sustentáculo da sua existência. A alimentação saudável é fundamental ao desenvolvimento integral e harmonioso de todos os indivíduos e os hábitos, práticas e comportamentos alimentares adquiridos durante a infância, tendem a perdurar (Peres, 1998). A alimentação envolve sempre uma eleição de alimentos, que se afirma como um processo espontâneo e complexo que pode ser delimitado por fatores cognitivos, sociais, económicos, emocionais, psicológicos, afetivos e culturais (NUNES; BREDA, 2001).

Segundo a Organização Mundial de Saúde (OMS) (WHO, 2008), a situação nutricional é resultante de uma alimentação insuficiente, excessiva ou desequilibrada e constitui, no tempo 
atual, um dos principais problemas de saúde no mundo. De acordo com a Direção-Geral da Saúde (DGS, ca. 2012) do Governo da República Portuguesa, uma alimentação adequada e o consequente melhoramento do estado nutricional dos cidadãos tem reflexos claros na prevenção e no controlo das doenças mais prevalentes a nível nacional: cardiovasculares, oncológicas, diabetes, obesidade. O primeiro estudo realizado pelo Sistema Nacional de Vigilância Nutricional Infantil - COSI Portugal, com uma amostra representativa formada por 3765 crianças, decorreu no ano letivo de 2007/2008 (DGS, ca. 2012). Os resultados alcançados caraterizam o estado nutricional infantil de crianças portuguesas entre os 6 e os 8 anos de idade e também as caraterísticas sócio demográficas e familiares, assim como a descrição do ambiente escolar ao nível da alimentação, prática de atividade física e atividades promotoras de estilos de vida saudáveis. O valor médio do índice de massa corporal (IMC) mais elevado foi encontrado na Região Autónoma dos Açores $\left(17,9 \mathrm{~kg} / \mathrm{m}^{2}\right)$ e o mais baixo na região Algarve $\left(16,2 \mathrm{~kg} / \mathrm{m}^{2}\right)$, apresentando a região Alentejo um valor de $16,9 \mathrm{~kg} / \mathrm{m}^{2}$. O estudo revela, também, que 95,6\% das crianças toma o pequeno-almoço todos os dias; os alimentos consumidos frequentemente (quatro ou mais vezes por semana) correspondem, na sua maioria, a alimentos de baixa densidade nutricional designadamente pizza, batata frita em casa e de pacote, hambúrgueres, salsichas, snacks, pipocas ou aperitivos salgados, com consumos acima de $90 \%$. Apenas $12 \%$ das escolas oferece fruta fresca aos alunos e $91,8 \%$ das escolas fornece leite.

De acordo com a United Nations Children's Fund (UNICEF, 2013), pensa-se que aproximadamente 870 milhões de pessoas no mundo estão desnutridas. Entre elas, cerca de 165 milhões com idade inferior a 5 anos sofrem de atrofiamento ou apresentam-se cronicamente desnutridas, e mais de 100 milhões são consideradas abaixo do peso. A insuficiência de alimentos ou uma dieta desequilibrada, deficitária em vitaminas (por exemplo, vitamina A) e minerais (por exemplo, iodo, ferro e zinco) pode deixar bebés e crianças vulneráveis a condições específicas ou uma série de infeções que podem conduzir a deficiências físicas, sensoriais ou intelectuais.

O bem-estar nutricional é identificado como um fator relevante para a maximização do crescimento, a preservação da saúde, melhoria da qualidade de vida e longevidade. Os problemas de saúde associados à nutrição, especificamente a obesidade e a constipação crónica, apresentam-se mais comuns em pessoas com Deficiência Intelectual (DI) comparativamente à demais população (BURKART; FOX; ROTATON, 1985; STEWART; BEANGE; MACKERRAS, 1994). Ações de triagem de risco de nutrição são recomendadas em virtude de permitirem o reconhecimento e a gestão dos problemas de nutrição, entre a população com DI de qualquer idade. Estas ações podem ser realizadas por qualquer pessoa que esteja diretamente ligada a pessoas com deficiência, detentores de conhecimento básico de nutrição, com recurso a ferramentas de rastreio simplificado. Estas ferramentas devem usar indicadores de peso e das suas alterações, como sejam habilidades no processo de toma da refeição, a aparência física, a avaliação simples da alimentação e a ingestão de líquidos (ADA, 1996). As crianças com DI também podem ter dificuldade em alimentar-se ou necessitarem de tempo adicional ou ajuda para comer e é provável que, em algumas pessoas, o que se supõe ser associado à deficiência ou a problemas de saúde e desperdício de alimentos possa estar relacionado com problemas de alimentação (UNICEF, 2013). A definição de excesso de peso e de obesidade é, no tempo atual, assunto de discussão científica, pois não se apresenta ainda um método de medição direta da gordura corporal simples e pouco dispendioso e de simples reprodução. A dieta mediterrânica constitui um excelente modelo para uma vida saudável existindo uma consciência geral, e 
evidência científica, da relação entre a dieta mediterrânica e a saúde (APN, 2012). O vocábulo

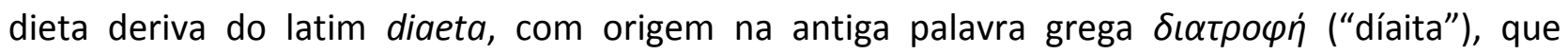
significa "estilo de vida equilibrado" e não apenas "comer" e é isso que a dieta mediterrânica efetivamente parece definir. Trata-se de uma forma de entender a vida e comer com base em produtos agrícolas locais, receitas e métodos de confeção de cada local, passada de geração em geração, partilhado socialmente as refeições, comemorações e tradições. Associa-se a prática da atividade física diária moderada e corresponde a um estilo de vida que a ciência moderna nos convida a tomar para benefício da nossa saúde. Pelas razões apontadas, em 16 de novembro de 2010, em Nairobi, no Quénia, a UNESCO Intergovernmental Committee for the Safeguarding of Intangible Cultural Heritage concordou com a inclusão da alimentação mediterrânica na Lista do Património Mundial da Humanidade. Em 4 de dezembro de 2013, na 8a Sessão do Comité Intergovernamental da Organização, foi votada favoravelmente o alargamento a outros Estados nomeadamente a Portugal, Croácia, Chipre, Espanha, Marrocos, Itália e Grécia.

\subsection{Escolas Promotoras de Saúde}

De acordo com Santos (1983, p. 23), a alimentação é um dos "principais fundamentos da saúde física, mental e espiritual". A alimentação carateriza-se como um processo de seleção de alimentos, que pode ser definido por fatores cognitivos, sociais, económicos, emocionais, psicológicos, afetivos e culturais (NUNES; BREDA, 2001). A alimentação desempenha, por isso, um papel importante na vida do ser humano, pois: a) "assegura a sobrevivência"; b) "fornece energia e nutrientes necessários ao bom funcionamento do organismo"; c) "contribui para a manutenção do nosso estado de saúde físico e mental"; e) "desempenha um papel fundamental na prevenção de certas doenças (por exemplo, obesidade, doenças cardiovasculares, diabetes, certos tipo de cancro, etc.)"; e f) "contribui para o adequado crescimento e desenvolvimento das crianças e adolescentes" (CANDEIAS et al. 2005, p. 5).

Segundo Viana (2002), os hábitos alimentares constituem um importante comportamento de saúde. O autor defende que a adoção de uma alimentação saudável requer uma seleção apropriada dos alimentos de acordo com o seu sabor, as aprendizagens familiares e os fatores psicossociais. Assistimos, atualmente a uma alteração nos padrões alimentares a nível global, com um incremento do consumo de gorduras e açúcares, inclusive nos países mais pobres. As referidas mudanças no comportamento alimentar podem elucidar acerca do aumento da obesidade infantil, em consequência da ampliação do consumo de proteínas, glícidos e de gorduras (NICKLAS et al., 2001). Paralelamente a este aumento, regista-se uma diminuição do consumo de frutas e de produtos hortícolas, indicando as estimativas que apenas entre $7 \%$ e $30 \%$ das crianças ingerem cinco ou mais peças de fruta recomendadas por dia (KANN et al., 1996) e consomem mais 30\% das calorias aconselhadas (BERENSON et al., 1995).

Os padrões alimentares, nomeadamente, as idas a restaurantes fast-food, o consumo de bebidas açucaradas e o aumento das porções alimentares associados ao tipo de alimentos consumidos podem conduzir ao excesso de peso (GREENWOOD; STANFORD, 2008; NICKLAS; BARANOWSI; CULLEN; BERESON, 2001). Verifica-se um aumento das porções alimentares consumidas por crianças e adolescentes, sobretudo quando as refeições decorrem fora de casa, 0 que concorre para um aumento de peso e, consequentemente, à obesidade (NICKLAS; BARANOWSI; CULLEN; BERESON, 2001). 
A infância constitui um período especialmente importante para a aquisição de hábitos e padrões alimentares adequados, sendo que o controlo parental pode influenciar de forma negativa esta aquisição. Pais que estabelecem um controlo apertado na alimentação dos seus filhos podem interferir com a capacidade da criança regular o que consome, levando a uma falta de autonomia face ao que elegem comer e concludentemente ao excesso de peso (ROBINSON et al., 2001).

De acordo com a Direção-Geral da Educação do Ministério da Educação Português (DGE, 2013), a promoção e educação para a saúde em meio escolar consiste em munir de conhecimentos, atitudes e valores, as crianças e os jovens, para que decidam adequadamente em relação à sua saúde e bem-estar, físico, social e mental, e ainda, de forma interventiva, na saúde dos que lhes estão próximo. Em novembro de 1986 decorreu no Canadá a primeira grande conferência internacional acerca da Promoção da Saúde, de onde surgiu a Carta de Ottawa. A Conferência convocou a OMS, entre demais organismos internacionais, na defesa da saúde nos diferentes contextos, por se entender globalmente a responsabilidade sobre esta problemática. Portugal foi um dos países participantes, tendo ratificado o documento orientador que dela adveio. Entre outros setores, o educativo estrutura-se na edificação de um bem-estar global. Desde então, o Gabinete Regional para a Europa da OMS criou a Rede Europeia de Escolas Promotoras de Saúde. Esta iniciativa objetiva a promoção da saúde e a demonstração do impacto da promoção da saúde no contexto escolar. Em 1995, Portugal adere a este movimento integrado por 46 países membros, que na atualidade se materializa na plataforma Schools for Health in Europe (SHE) (http://www.schools-for-health.eu/she-network).

A SHE defende que a promoção da saúde integre as políticas de desenvolvimento da educação e da saúde na Europa. O desenvolvimento de esforços conjuntos, em colaboração internacional, objetiva a criação de redes sustentáveis, inovadoras e convergentes. Segundo a International Union Health Promotion and Education (ca. 2014), os princípios promotores da saúde em meio escolar, através de uma escola promotora de saúde listam-se em: a) promover a saúde e bem-estar dos alunos, b) melhorar os resultados escolares, c) defender os princípios de justiça social e equidade, d) fornecer um ambiente seguro e de apoio, e) fomentar a participação dos alunos e desenvolver o seu empoderamento, f) articular as questões e os sistemas da saúde e da educação, g) abordar as questões de saúde e o bem-estar de todo o pessoal da escola, h) colaborar com os pais dos alunos e com a comunidade, i) integrar a saúde nas atividades correntes da escola, no programa escolar e nos critérios de avaliação, j) estabelecer objetivos realistas com base em dados precisos e com sólidas evidências científicas; e (k) procurar uma melhoria constante através de uma supervisão e a avaliação contínua.

O reconhecimento da importância da promoção da saúde da população escolar alicerça o Despacho no 2506/2007, de 20 de fevereiro da República Portuguesa. Neste normativo, o legislador estabelece que os projetos educativos dos agrupamentos de escolas/escolas não agrupadas devem incluir o projeto de Educação para a Saúde (EpS), com a designação de um professor coordenador estruturando-se organizacionalmente a intervenção em meio escolar na capacitação com vista à promoção da saúde. A alimentação constitui uma área prioritária de intervenção nas escolas devendo ser tratada, independentemente dos conteúdos curriculares de algumas disciplinas, no projeto de EpS, de acordo com a DGE (2013). Objetiva a melhoria do estado de saúde global dos jovens, a inversão da tendência crescente de perfis de doença 
associadas a uma deficiente nutrição e a promoção da saúde dos jovens, especificamente em matéria de alimentação saudável e atividade física.

\section{METOdOLOGIA}

\subsection{Desenho metodológico}

Esta investigação compreendeu quatro fases. Uma primeira, corresponde à construção de um quadro teórico e concetual. Abordaram-se as NEE e as Dificuldades Intelectuais e Desenvolvimentais (DID), com base na literatura da especialidade. Fez-se, ainda, uma revisão sobre a importância da alimentação na promoção da saúde. Como se revelou, são escassos os estudos que caraterizam os comportamentos alimentares de crianças com DI.

A segunda fase procurou caraterizar os hábitos alimentares das alunas e as práticas de higienização social das mãos antes e após a refeição, além das normas socialização à mesa durante uma refeição. Nesta fase, foram também avaliados os dados antropométricos dos sujeitos estudados, registando-os numa tabela.

$\mathrm{Na}$ terceira fase, foi concebida e implementada uma intervenção didática de capacitação dos sujeitos participantes no estudo. Foram planeadas atividades a desenvolver em espaço escolar e na comunidade e definidas estratégias a adotar. Após a conceção das sessões, delineámos um cronograma que foi sujeito a alterações, no decurso do projeto, em consequência de acontecimentos inicialmente não previstos. A implementação da sequência didática aconteceu entre fevereiro e maio de 2014.

Por fim, numa quarta fase, desenvolveu-se um novo ciclo de observação, que se prolongou até sete dias após a finalização da sequência didática de capacitação. Os novos registos dos comportamentos observados permitiram a inferência da avaliação do impacto da sequência didática.

A conceção de um programa ou de uma ação de melhoramento e a eficácia da sua implementação dependem, essencialmente, do conhecimento e da compreensão da realidade que forma o terreno social de aplicação. Nesse sentido, procurámos caraterizar as atitudes e as rotinas, em refeitório escolar, no período de almoço, percebendo os hábitos alimentares e os comportamentos das alunas objeto de estudo.

Por esta razão, privilegiámos um contexto de descoberta, enquanto ponto de partida, num processo indutivo exploratório. A pergunta pivô - Em que medida um programa de capacitação das alunas com DI influencia a alteração das suas práticas alimentares, em ambiente escolar? - dirigiu-nos a uma abordagem metodológica que possibilitasse um estudo situacional, que se prende com o diagnóstico de um problema num determinado contexto e que procura a sua resolução, nesse mesmo contexto (Sousa, 2005). Neste trabalho foram definidos dois grandes objetivos: desenvolver nas crianças com DI atitudes positivas face a todos os alimentos saudáveis e estimular a aceitação de uma alimentação saudável e diversificada como forma de promoção da saúde. 


\section{2 Área de estudo}

Este estudo desenvolveu-se em Portugal, num agrupamento de escolas do distrito de Portalegre, localizado na sub-região do Alto Alentejo, que inclui 15 municípios, com uma área de $6239 \mathrm{~km}^{2}$ e uma população estimada de 118410 habitantes (48\% do sexo masculino), segundo os Censos de 2011 (INE, 2014), correspondendo a 1,12\% da população nacional.

\subsection{Sujeitos}

Os sujeitos participantes no estudo foram seis alunas com idades compreendidas entre os 14 e os 17 anos de idade que frequentavam os 7ㅇ, 8 e 9o anos de escolaridade. As alunas correspondem à população que reside numa instituição de acolhimento de menores de idade e são oriundas de outras instituições que as receberam em períodos anteriores, após a sua saída do núcleo familiar. A investigação decorreu no quotidiano escolar. Os episódios observacionais aconteceram durante o período do intervalo das atividades para o almoço e a sequência pedagógica no período de atividades letivas, a quando da permanência de todas as alunas na sala de apoio.

\subsubsection{Sujeito 1}

O sujeito 1 reporta a uma aluna nascida em 10 de abril de 1997. Frequenta o 9o ano de escolaridade. Apresenta perturbações do espectro do autismo e leucomalácia periventricular. Esta deficiência estrutural traduz uma necrose multifocal da substância branca, que atinge até o ângulo externo do ventrículo lateral, considerada uma zona de fronteira de vasculaziração. A causa da leucomalácia é uma hipoxia que tende a gerar lesões generalizadas nos fetos mais novos e lesões focalizadas nos fetos mais desenvolvidos, sendo causa de paralisia cerebral e de DM mental.

Considerando as funções do corpo, o sujeito 1 apresenta limitações, de acordo com a versão para crianças e jovens da Classificação Internacional da Funcionalidade, Incapacidade e Saúde (CIF-CJ, s.d.; OMS, 2004), nas funções ao nível do pensamento (b160.3), nas funções cognitivas de nível superior (b164.3), nas funções psicomotoras (b147.3) e nas funções emocionais (b152.3). No que respeita à atividade e participação denotam-se limitações ao nível do cálculo e raciocínio matemáticos (d150.3), da escrita (d170.2) e dificuldade em controlar o seu próprio comportamento (d250.4). Os fatores ambientais apresentam-se como facilitadores: conhecidos, pares, colegas e membros da comunidade $(e 325+2)$ e trabalho em parceria desenvolvido por todos os profissionais $(e 360+3)$. O sujeito domina as técnicas de leitura e interpreta textos simples. A sua caligrafia apresenta traçado pouco seguro. Demonstra interesses muito reduzidos nas atividades e tarefas que lhe são apresentadas. Gosta de usar o computador para escrever frases e realizar pesquisas de imagens e usa máquina fotográfica. Evita atividades que envolvem interação social e, no recreio, brinca rodando repetidamente cartões aos quais se apega. É agressiva e age, por vezes, destruindo objetos. A resistência à alteração de rotinas é grande. Demonstra rejeição a determinadas texturas e a temperaturas baixas sentidas a nível ambiental e alimentar. A aluna beneficia das medidas educativas de apoio pedagógico personalizado e currículo específico individual, previstas no arto 16 do Decreto-Lei no 3/2008, de 7 de janeiro. No ano de 2010, integrou a instituição e inicia a frequência letiva no agrupamento de escolas perdurando antes as situações até ao momento atual. 


\subsubsection{Sujeito 2}

O sujeito 2 corresponde a uma aluna nascida em 20 de junho de 1996. Desde o ano de 2002 que reside na instituição que a acolhe. Iniciou os estudos no agrupamento no ano letivo de 2003/2004 e frequenta, atualmente, o 9o ano de escolaridade. Segundo relatório médico, sofre de DM grave. De acordo com o seu Plano Educativo Individual (PEI), as funções do corpo apresentam comprometimento ao nível das funções mentais (CIF-CJ, s.d.; OMS, 2004): funções da orientação no espaço e no tempo (b114.1), funções intelectuais (b117.3), funções psicossociais globais (b122.3), funções da atenção (b140.3), funções da memória (b144.3), funções psicomotoras (147.2), funções mentais da linguagem (b167.3) e do cálculo (b172.3). As funções da voz e da fala apresentam comprometimento: funções da voz (b310.3), articulação (b320.3) e de fluência do ritmo da fala (b330.3). As funções neuromusculoesqueléticas e funções relacionadas com o movimento apresentam compromisso: as funções relacionadas com a mobilidade das articulações (b710.3), as funções das articulações (b715.2), funções relacionadas com a força (b730.1) e o tónus muscular (b735.1), reflexos motores (b750.1), músculos e funções do movimento (b780.2).

$\mathrm{Na}$ atividade e participação a aprendizagem é facilitada através da interação com objetos (d131.3), revela comprometimento na aquisição de informação (d132.3), na aquisição de linguagem (d133.3), aquisição de conceitos (d137.3), na aprendizagem da leitura (d140.3) e da escrita (d145. 1), em aprender a calcular (d150.3), em dirigir a atenção (d161.3). Ao nível das tarefas e exigências gerais apresenta dificuldade em iniciar uma tarefa (d210.3) porém realiza algumas rotinas diárias (d230.2). Ao nível da comunicação revela comprometimento (d350.3), na discussão (d355.3). No que respeita a autocuidados revela uma lentidão significativa e necessita que the relembrem os procedimentos a ter ( $d 510.2 ; d 520.2 ; d 530.2)$. Os fatores ambientais como facilitadores: conhecidos, pares, colegas e membros da comunidade $(e 325+3)$ e trabalho em parceria desenvolvido por todos os profissionais $(\mathrm{e} 360+3)$.

O sujeito beneficia das medidas educativas de apoio pedagógico personalizado e de currículo específico individual, previstas no arto 16 do Decreto-Lei no 3/2008, de 7 de janeiro (alíneas "a" e "e"). A aluna não domina as técnicas de leitura demonstrando conhecer apenas algumas letras e revela comprometimentos ao nível da interpretação. Conhece números até 20 e associa-os à quantidade. A sua caligrafia apresenta traçado muito cuidado. Demonstra pouca concentração, muita passividade, falta de iniciativa e de autonomia. Adere às atividades propostas e gosta de usar o computador para escrever palavras que copia de modelos, jogar e escutar música. Demonstra também gosto em observar os colegas nas atividades livres no intervalo porém, não se envolve interagindo com eles. É meiga e tímida. Estabelece pouca comunicação com os pares e os adultos apesar de se ter assistido a um incremento na comunicação com os adultos particularmente na aproximação voluntária para os saudar ou fazer curto comentário.

\subsubsection{Sujeito 3}

O sujeito 3 é do sexo feminino e nasceu em 25 de dezembro de 1997. De acordo com relatório constante do seu $\mathrm{PEI}$, a aluna apresenta défice cognitivo com impacto comportamental. Viveu momentos de grande instabilidade, forçada a um permanente corte de laços. Foi retirada do seio da família e integrou três centros de acolhimento anteriores àquele em que atualmente 
vive. Os relatórios pedagógicos e psicológicos registam alterações graves de comportamento. Apresenta-se, de acordo com a última atualização do seu PEl, a caracterização dos indicadores de funcionalidade ao nível da atividade e participação, das funções e estruturas do corpo e dos fatores ambientais, por referência à CIF-CJ (s.d.) e à OMS (2004). No que se refere às funções do corpo, ao nível das funções mentais, registam-se comprometimentos nas funções intelectuais (b117.2), funções da energia e dos impulsos (b130.2), funções da atenção (b140.2), funções emocionais (b152.2), funções cognitivas básicas (b163.2), cognitivas de nível superior (b164.3), funções mentais da linguagem (b167.2), funções do cálculo (b172.3). É ainda referida a dificuldade moderada em controlo de impulsos (b1304.2). Na atividade e participação denota-se dificuldade em aprender a ler (d140.3), a escrever (d145.3), a calcular (d150.3), em concentrar a atenção (d160.3), em dirigir a atenção (d161.3), em pensar (d163.3), em tomar decisões (d77.2) e em controlar o seu próprio comportamento (d250.3). Os fatores ambientais facilitadores são produtos e tecnologias gerais para educação $($ e1300+2), conhecidos, pares, colegas, e membros da comunidade (e325+3), outros profissionais (e360.3). É apontada a ausência da família como uma barreira grave (e310.3).

A aluna não domina as técnicas de leitura. Conhece apenas algumas letras. Consegue interpretar mensagens orais. Conhece números até 100 mas não os associa à quantidade. A sua caligrafia apresenta traçado muito irregular e seguro consequente de tremores que por vezes apresenta. Demonstra pouca concentração. Gosta de estar junto dos colegas da turma de referência, durante os intervalos. Apresenta momentos de aceitação das indicações que contrariam a sua vontade com outros de franco descontrolo quando é contrariada. A aluna demonstra, frequentemente, grande agitação e instabilidade o que a leva a empenhar-se durante períodos muito curtos na execução de tarefas. É comunicativa e sociável com os pares e os adultos porém apresenta também momentos de agressividade e descontrolo. O sujeito beneficia das medidas educativas previstas no arto 16 do Decreto-Lei ํo 3/2008, de 7 de janeiro, em particular, de apoio pedagógico personalizado e de currículo específico individual.

\subsubsection{Sujeito 4}

O sujeito 4 é do sexo feminino e nasceu em 21 de agosto de 1997. O seu historial clínico revela alterações comportamentais com perturbações de pânico associadas a excitação e atraso mental. Vive na atual instituição de acolhimento desde setembro de 2012. O seu PEI regista a caraterização dos indicadores de funcionalidade ao nível da atividade e participação, das funções e estruturas do corpo e dos fatores ambientais, por referência à CIF (s.d.) e à OMS (2004) que se apresentam. Nas funções do corpo é referida dificuldade grave nas funções intelectuais (b117.3). Relativamente à atividade e participação registam-se comprometimentos em observar (d110.2), em imitar (d130.2), em adquirir linguagem (d133.1), em adquirir conceitos (d137.2), e aprender a ler (d140.3), a escrever (d145.3) e a calcular (d150.3), aquisição de competências (d155.2), em concentrar a atenção (d160.2) e em dirigir a atenção (d161.2). Ao nível das tarefas e exigências gerais os comprometimentos revelados prendem-se em levar a cabo uma tarefa única (d201.2), em levar a cabo a rotina diária (d230.2), em controlar o seu próprio comportamento (d250.2). Quanto à comunicação, revelam-se dificuldades em comunicar e receber mensagens não verbais (d315.2), em comunicar e receber mensagens escritas (d325.4). Os fatores ambientais facilitadores são produtos e tecnologias $(e 125+2)$, conhecidos, pares, colegas e membros da comunidade $(e 325+3)$ e pessoas em posição de autoridade $(e 330+3)$. 
A aluna não domina as técnicas de leitura. Conhece e escreve algumas letras. Consegue interpretar mensagens orais. Conhece os números até 200 e realiza operações muito simples. Realiza os trabalhos com empenho. A aluna demonstra muita vivacidade e alegria. Gosta de brincar e de dançar e também de estar próxima dos colegas da turma de referência, durante os intervalos. É uma menina alegre que estabelece facilmente relação com adultos e com os pares. A aluna domina técnicas de utilização das tecnologias de informação e comunicação, nomeadamente a pesquisa dirigida e livre na Internet. 0 sujeito 4 beneficia das medidas educativas previstas no arto 16 do Decreto-Lei no 3/2008, de 7 de janeiro, em particular as definidas nas alíneas "a" e "e".

\subsubsection{Sujeito 5}

O sujeito 5, do sexo feminino, reside na atual instituição de acolhimento desde 2009. Nasceu em 19 de fevereiro de 1999. Tem um quadro de microcefalia, provocada por uma insuficiência no desenvolvimento do crânio e do encéfalo, dando origem a um crânio de tamanho reduzido e um cérebro inferior ao normal, conferindo uma DM grave. Integra o regime educativo previsto no Decreto-Lei no 3/2008, de 7 de janeiro, beneficiando das medidas educativas de apoio individualizado (art. ${ }^{\circ} 17^{\circ}$ ) e de currículo específico individual (art. ${ }^{\circ} 21$ ) $)$.

A caraterização dos indicadores de funcionalidade ao nível da atividade e participação, das funções e estruturas do corpo e dos fatores ambientais, por referência à CIF (s.d.) e OMS (2004) é a que se apresenta. Ao nível das funções do corpo referem-se compromissos nas funções mentais: funções intelectuais (b122.2), nas funções do temperamento e da personalidade (b126.2), nas funções da atenção (b140.2), nas funções da memória (b144.2), nas funções psicomotoras (b147.1), nas funções cognitivas de nível superior (b167.3), nas funções mentais da linguagem (b167.2), nas funções do cálculo (b172.3). Ao nível das funções da voz e da fala apresenta dificuldade nas funções de articulação (b320.3) e das funções da fluência e ritmo da fala (b330.3). Na aprendizagem e aplicação de conhecimentos registam-se comprometimento na aquisição de conceitos (d137.3), em aprender a ler, a escrever e a calcular (d140.3; d145.3; d150.3), na aquisição de competências (d155.2), em concentrar a atenção, em dirigir a atenção (d161.2), em ler (d166.4), em escrever (d170.3) e em calcular (d172.3). Ao nível da comunicação manifesta dificuldade em comunicar e receber mensagens orais (d310.3), em comunicar e receber mensagens não verbais (d315.3), em comunicar e receber mensagens escritas (d325.4) e em falar (d330.3). Os fatores ambientais facilitadores são produtos e tecnologias (e130+2) e de apoio e relacionamento: conhecidos, pares, colegas e membros da comunidade são facilitadores substanciais (e325+3) e pessoas em posição de autoridade na escola e na instituição (e330+3). Apresenta-se como barreira a ausência de uma favorável estrutura familiar (e310.3).

A aluna conhece algumas letras, mas não é leitora. Também conhece números e associaos a quantidades até sete. É empenhada e cuidadosa na execução dos trabalhos. É muito afetiva com o adulto e demonstra agrado pelo contacto físico que procura recorrentemente. É alegre e gosta de brincar durante os intervalos. A aluna domina a utilização do computador, nomeadamente a pesquisa na Internet, sendo esta uma das suas atividades favoritas. 


\subsubsection{Sujeito 6}

O sujeito 6, do sexo feminino, nasceu em 29 de julho de 1999. Desde 2010 que reside na instituição atual, após ter vivido desde 2004 em mais dois centros de acolhimento. Frequenta o 70 ano de escolaridade. A aluna detém grave défice cognitivo, alguns problemas de linguagem e uma ligeira limitação psicomotora. No que se refere às funções do corpo, com base na CIF-CJ (s.d.) e OMS (2004), revela compromisso nas funções intelectuais (b117.3), nas funções psicossociais globais (b122.3), nas funções emocionais (b152.3), nas funções cognitivas básicas (b163.3), nas funções mentais da linguagem (b167.2). Na atividade e participação apresenta dificuldade em aprender a ler (d140.2), em aprender a escrever (d145.2), em aprender a calcular (d150.2), em concentrar a atenção (d160.2), em levar a cabo tarefas múltiplas (d220.2), em levar a cabo a rotina diária (d230.1), em controlar o seu próprio comportamento (d250.2), em comunicar e receber mensagens orais (d310.2) nas interações interpessoais complexas (d720.1), na vida comunitária (d910.2). Constituem-se como fatores ambientais facilitadores os conhecidos, pares, colegas, vizinhos e membros da comunidade (e325+3), pessoas em posição de autoridade (e330+3) e como barreiras a família (e310.3) e as atitudes individuais dos membros da família (e410.3).

A aluna conhece as letras e os números mas tem muitas dificuldades em ler e em produzir enunciados escritos, no entanto, consegue reproduzir textos ou outros enunciados escritos com boa caligrafia. Realiza cálculos simples adicionando e subtraindo. Consegue utilizar as tecnologias de informação e comunicação com bastante autonomia, nomeadamente a pesquisa orientada e livre na Internet, de acordo com temas do seu interesse (música, jogos e penteados). Encontra-se abrangida pelo Decreto-Lei no 3/2008 de 7 de janeiro, beneficiando das medidas educativas previstas nas alíneas a) e e) do arto 160 .

\subsection{Instrumentos}

Baseando-nos em Best (1982) e Correia (2009), considerou-se vantajoso o uso de guiões estruturantes da observação, elaborados com fundamento e na convergência dos objetivos da investigação. Decorrente da listagem elaborada dos aspetos acerca dos quais se apresentava necessário recolher informação, foram criadas grelhas de registo de observações que contribuíram para a objetivação e a sistematização do processo: a) grelha de observação na linha de distribuição das refeições, para registo dos alimentos dispensados e recolhidos pelas alunas; b) grelha de observação dos tabuleiros junto ao balcão de entrega no final da refeição, elementos deixados totalmente, parcialmente e totalmente ingeridos.

Os instrumentos usados foram produzidos propositadamente para o efeito, alicerçandoos na perspetiva do estudo, tomando com referência autores consultados. A opção de construir as grelhas prendeu-se com o facto de não existirem publicados, até ao momento, instrumentos que se adequassem à população com as características a que este estudo se reporta. A validação dos instrumentos foi realizada com a apreciação por parte de dois juízes externos ao estudo.

\subsection{Recolha da informação}

A observação decorreu em duas fases. Iniciou-se com observações que orientaram os investigadores e permitiram a obtenção de uma visão global da situação. Realizaram-se depois dois ciclos de observações focalizadas, centradas nas situações e nos elementos essenciais para a 
problemática a investigar. As observações resultaram de uma planificação e decorreram de forma sistemática, com toda a objetividade possível. O primeiro ciclo de observações decorreu entre 3 de fevereiro e 21 de fevereiro de 2014. Os 15 episódios de observação ocorreram em dias consecutivos, relativos a todos os campos considerados, num total de 90 registos. 0 segundo ciclo de observações decorreu após a capacitação. Foram elaborados registos relativos a 16 episódios de hábitos alimentares.

\subsection{Tratamento da informação}

Huberman e Miles (1994) consideram que a triangulação pode ter múltiplos significados, em que um deles tem a ver com a possibilidade de colaboração entre investigadores. Porém, postulam que é difícil, no mundo da investigação empírica, haver convergência total, podendo mesmo acontecer que as fontes, por exemplo, sejam inconsistentes ou mesmo contraditórias. Ainda que a objetividade não seja alcançada, o investigador deve buscar o rigor dos processos de análise e dos resultados. Maxwell (1996) e Lincoln e Guba (1985) propõem que, além da triangulação de métodos, e com o fim de alcançar uma compreensão mais profunda do fenómeno em estudo, se atenda à opinião dos participantes procurando a validação pelas pessoas envolvidas.

A fim de tratarmos metodicamente a informação obtida nos distintos episódios e podermos quantificar estes dados qualitativos, socorremo-nos de "um conjunto de técnicas de análise das comunicações, que utiliza procedimentos sistemáticos e objetivos de descrição do conteúdo das mensagens" (BARDIN, 1994, p. 30), classificando-as ou categorizando-as (CARTWRIGHT, 1974), a que se dá o nome de análise de conteúdo ou codificação. Pode considerar-se que um discurso que é desmembrado para se edificar um outro por atribuição ou agrupamento de traços de significação, resultado de uma relação dinâmica entre as condições de produção do discurso a analisar, e as condições de produção da análise.

De entre as várias vantagens da análise de conteúdo, salienta-se o facto de a técnica referida poder incidir sobre material não-estruturado, como por exemplo anotação de observações (BARDIN, 1994). Para proceder à análise de conteúdo das observações começamos por traduzi-las para o papel, a partir das observações naturalistas efetuadas. Procedemos à síntese das observações por forma a resumirmos a informação recolhida. Este procedimento objetiva uma representação mais simples dos dados, crendo que desta forma a transcrição da realidade se mantém.

As fichas de registo preenchidas em ambos os ciclos observacionais foram minuciosamente analisadas advindo a criação de quadros síntese que concorreram para a caraterização dos hábitos alimentares das alunas e dos comportamentos de higiene e regras sociais, sendo colocadas à consideração da assistente operacional ${ }^{1}$ que realizou em paralelo as observações, a fim de encontrarem os elos comuns e a validade necessárias ao trabalho de análise realizado.

\footnotetext{
${ }^{1}$ No contexto português, um assistente operacional tem os seguintes conteúdos funcionais: funções de natureza executiva, de carácter manual ou mecânico, enquadradas em diretivas gerais bem definidas e com graus de complexidade variáveis; execução de tarefas de apoio elementares, indispensáveis ao funcionamento dos órgãos e serviços podendo comportar esforço físico; e responsabilidade pelos equipamentos sob sua guarda e pela sua correta utilização, procedendo, quando necessário, à manutenção e reparação dos mesmos (Lei no 35/2014, de 20 de junho).
} 
Ao longo dos ciclos de observação realizou-se um registo pormenorizado dos constituintes das refeições servidas às alunas, a coincidência ou não da refeição servida com a divulgada no menu para esse dia anotando-se a sopa, os acompanhamentos de vegetais e de fornecedores de hidratos de carbono, a fruta e o doce.

\section{PRIMEIRO CICLO OBSERVACIONAL}

Cada sujeito foi identificado com um código numérico de 1 a 6 . Após análise dos registos efetuados nos episódios de observação foram considerados apenas os que apresentavam concordância entre a investigadora e a assistente operacional. Diariamente, os registos foram analisados e comparadas as coincidências e as divergências destes, resultando do referido encontro os registos diários referentes aos episódios observacionais.

No sujeito 1 assiste-se a um comportamento alimentar carenciado em variedade e em quantidade, com base na Pirâmide Alimentar Mediterrânea (APD, 2014). O pão foi, por iniciativa do sujeito, partido e colocado na sopa e ingerida a mistura de seguida. Também comeu pão colocando-lhe carne no interior, preparando um sanduíche. O acompanhamento de arroz foi rejeitado em função da textura granulosa, apesar da insistência da assistente operacional que acompanhava a refeição. A carne servida em fatias foi, também, rejeitada, porém, quanto servida em pequenos pedaços foi, quase sempre, tolerada e ingerida. Entre o pescado servido, o atum foi sempre consumido. O pudim foi o doce preferido, rejeitando-se a gelatina e o iogurte.

O sujeito 2 ingeriu a totalidade do pão, do acompanhamento fornecedor de glícidos e de doce servidos, durante os 15 episódios de observação. A sopa foi ingerida em 93,3 \% dos casos, o acompanhamento de vegetais em $69,2 \%$, a fruta em $66,7 \%$, a carne em $66,7 \%$, o peixe em 50,0 $\%$ e a água em $26,7 \%$ dos episódios.

A fruta, particularmente a banana, foi recusada em alguns dos episódios. A carne de bovino fatiada e o peixe servido à posta não foram ingeridos assim como os vegetais, nomeadamente o tomate. A água também ficou por tomar em alguns dos episódios. Verificou-se que, por vezes, a aluna solicitava e comia alimentos, mais concretamente o pão, o acompanhamento fornecedor de glícidos e o doce, de colegas que não tinham intenção de os ingerir, que não foram contabilizados nos episódios de observação.

O sujeito 3 ingeriu a totalidade do pão, do acompanhamento fornecedor de glícidos e de doce servidos, no decurso dos episódios de observação. A carne foi consumida em $66,7 \%$ dos momentos, a sopa em $80,0 \%$, a fruta em $66,7 \%$, a água em $53,3 \%$, os vegetais em $84,6 \%$ e o peixe em $50,0 \%$ dos episódios.

A carne de bovino não se apresentou como preferência da aluna. A salada mista, de alface e tomate, foi menos apreciada que a de apenas de alface. O pescado rejeitado foi a pescada (Merlucciidae), que foi servida assada. A aluna consumiu alimentos, nomeadamente pão, acompanhamento fornecedor de glícidos e em alguns casos doce, que solicitava às colegas que pretendiam não consumir os referidos alimentos. 
O sujeito 4 ingeriu a totalidade do pão, do acompanhamento fornecedor de glícidos e de doce servidos durante todos os episódios de observação. A fruta e o peixe foram consumidos em $50,0 \%$ dos casos, a carne em $44,4 \%$, os vegetais em $38,5 \%$, a água em $33,3 \%$ e a sopa em 26,7 $\%$. A carne de aves, nomeadamente de frango, não se mostrou como preferência da aluna e relativamente ao pescado foi o bacalhau (Gadidae) o menos apreciado. Preferiu comer a maçã (Malus) com casca e sem a cortar em pedaços, rejeitando a pera (Pyrus L.). A partilha da mesa com as colegas da sala foi bem aceite, gostando também de tomar a refeição na mesa de outros colegas que não frequentavam a sala de apoio. Mostrou-se atenta às suas conversas e observava os seus comportamentos, mantendo-se serena no decurso das refeições. Esta aluna consumiu alimentos, particularmente pão, acompanhamento fornecedor de glícidos e doce, pedindo-os às colegas que não os consumiam o que contribuiu para uma ingestão acima do indicado na dieta equilibrada.

O sujeito 5 ingeriu a totalidade do pão, do acompanhamento fornecedor de hidratos de carbono, sopa e de doce, no decurso do primeiro ciclo de observação. A carne e o peixe foram ingeridos em $66,7 \%$ dos episódios, o acompanhamento de vegetais em $46,2 \%$, a fruta em $41,7 \%$ e a água em 40,0 \%. A aluna consumiu alimentos pão e doce, pedidos às colegas. Relativamente aos doces, estes eram solicitados com muita insistência acabando por receber e, em consequência, os ingerir de forma excessiva de acordo com o indicado para uma dieta equilibrada.

O sujeito 6 ingeriu sopa em todos os episódios de observação. O doce foi ingerido $66,7 \%$ das vezes, a carne $44,4 \%$, a água $40,0 \%$, o peixe e o acompanhamento de hidratos de carbono $33,3 \%$, o pão $26,7 \%$, a fruta $16,7 \%$ e os vegetais em $7,7 \%$ dos episódios.

O comportamento alimentar apresentou-se muito aquém do recomendado segundo a Pirâmide Alimentar Mediterrânea. O pão ingerido foi, por iniciativa da aluna, partido em pedaços muito pequenos e colocado na sopa. A rejeição da carne foi justificada por a considerar rija. Entre o pescado servido a pescada foi a sua preferida. A partilha da mesa com as colegas da sala foi sempre bem aceite posicionando-se junto de diferentes colegas sem que acontecesse qualquer conflito.

\section{PLANO DE INTERVENÇÃO}

\subsection{Planificação da capacitação}

A planificação da sequência didática assentou nas fragilidades detetadas na análise dos dados obtidos a partir do primeiro ciclo observacional em contexto pré-refeição, durante o almoço e após a ingestão da refeição. A intervenção visava o reforço e favorecimento das potencialidades de cada sujeito, proporcionando o apoio necessário às dificuldades reveladas, garante do bem-estar e inclusão social.

Desenhámos e implementámos uma sequência didática com base nos hábitos alimentares no âmbito da EpS. Esta implementação decorreu em três períodos por constrangimento do calendário escolar. O primeiro período realizou-se entre 24 e 28 de fevereiro de 2014, sendo 
interrompido pela pausa letiva do Carnaval. O segundo período teve lugar entre 6 de março e 4 de abril de 2014, ao qual se seguiu a pausa letiva da Páscoa. O terceiro período teve início em 22 de abril e terminou em 7 de maio de 2014.

Esta sequência incorporou diversas temáticas, num total de 23 sessões (Tabela 1).

Tabela 1: Relação dos temas e do número de sessões da capacitação dos sujeitos.

\begin{tabular}{c|c}
\hline Temas & № de sessões \\
\hline Pão & 3 \\
Água & 2 \\
Doces & 2 \\
Fruta & 4 \\
Acompanhamento de glícidos & 2 \\
Acompanhamento de vegetais & 4 \\
Pescado, carne e ovos & 3 \\
Sopa & 3 \\
\hline
\end{tabular}

A planificação apresenta-se temática e generalista com base nas caraterísticas gerais do grupo. Em função dos sujeitos, a exploração dos instrumentos, decorreu com a interação e participação de todos os elementos, em consequência das adaptações feitas nas apresentações orais dos temas e exploração dos mesmos promovidos pelos autores.

Em conformidade, a aluna que apresentava competências de leitura e escrita participou na leitura dos instrumentos apresentados e analisados pelo grupo. Os instrumentos em suporte Power point ${ }^{\circledast}$ apresentaram, inicialmente, a informação escrita e, após a leitura desta, surgiram as imagens por forma a manter a prática da leitura e a interpretação. Elegeram-se imagens do agrado das alunas, nomeadamente dos seus cantores favoritos, objetivando facilitar o acompanhamento das atividades desenvolvidas. Foram produzidos instrumentos para aplicação de conhecimentos diferenciados, fundeados nas caraterísticas específicas dos sujeitos estudados. Pretendeu-se contemplar uma panóplia de estratégias e atividades que procurassem cumprir os objetivos traçados para o projeto que construímos. Ancorados nos gostos e desejos pessoais das alunas e recorrendo a reforços positivos, percorremos a sequência didática a que nos propusemos.

\subsection{Avaliação do impacto da capacitação}

Procurou-se perceber o impacto imediato que as sessões de capacitação tiveram nos comportamentos dos sujeitos do estudo, ainda que estejamos conscientes que a mudança de atitudes, nas idades indicadas e, particularmente, com os quadros de NEE descritos, é um processo complexo, função da motivação, do tempo de capacitação e do modo como são assimilados os conhecimentos e as práticas observadas, bem como da confiança depositada no educador.

Relativamente ao sujeito 1, após as sessões de capacitação, verificou-se um acréscimo na ingestão de todos os componentes da refeição (Figura 1). A água e os vegetais passaram de $0 \%$ para $50,0 \%$ e $42,8 \%$ respetivamente. O acompanhamento de hidratos de carbono, o peixe e o doce acresceram de $73,3 \%, 50,0 \%, 33,3 \%$ para $75,0 \%, 83,3 \%$ e $66,6 \%$, respetivamente e o pão 
de $26,6 \%$ para $50,0 \%$, a fruta de $16,6 \%$ para $53,8 \%$, a carne de $33,3 \%$ para $60,0 \%$ e a sopa de $20,0 \%$ para $62,5 \%$.

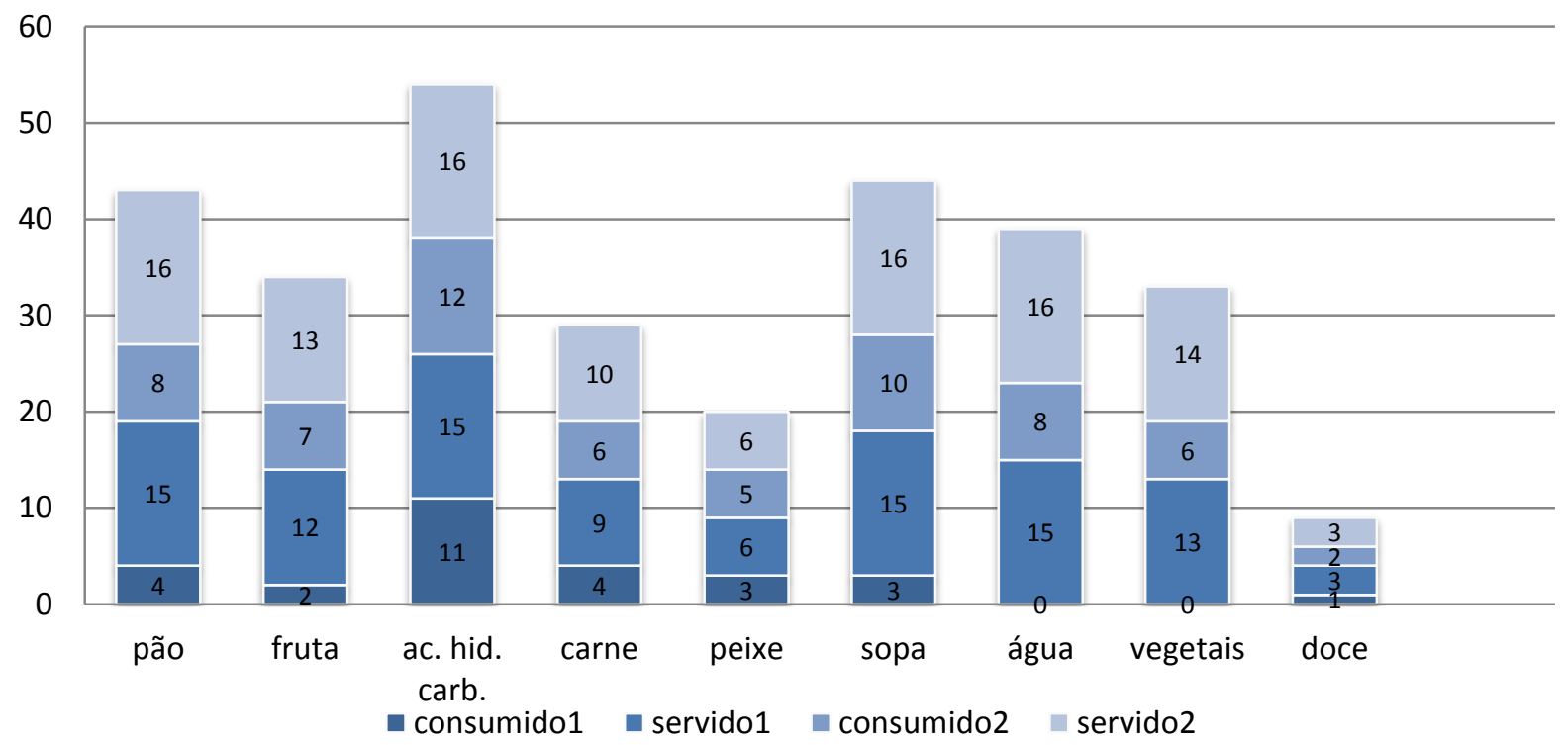

Figura 1: Comparação entre os alimentos consumidos e os alimentos servidos antes e após a capacitação do sujeito 1.

Em consequência das sessões de capacitação revelaram-se alterações nos hábitos alimentares do sujeito 2 (Figura 2).

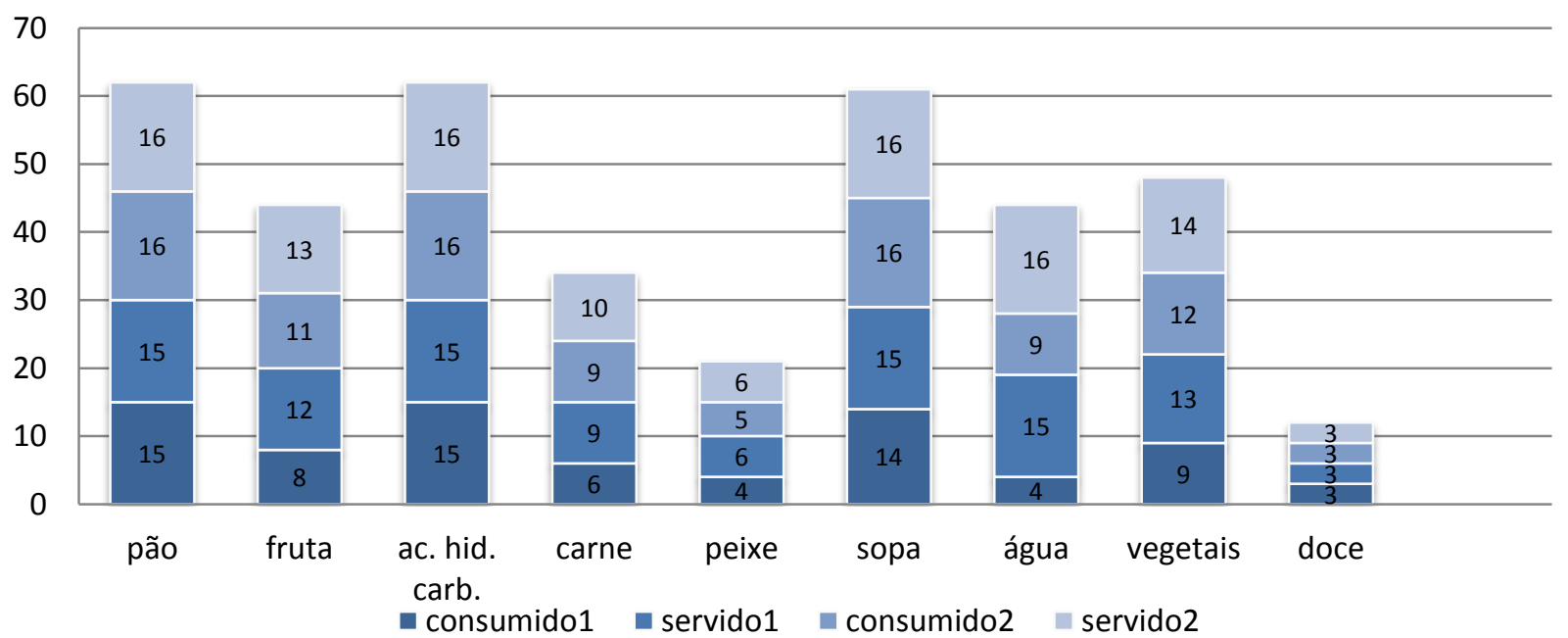

Figura 2: Comparação entre os alimentos consumidos e os alimentos servidos antes e após a capacitação do sujeito 2.

Comparativamente aos resultados registados no primeiro ciclo de observações assiste-se a um aumento da ingestão dos componentes da refeição que não eram tomados na totalidade. Manteve-se a total ingestão de pão, o acompanhamento de glícidos e do doce e aumentou o consumo de sopa de 93,3 \% para $100 \%$. A ingestão da carne passou de 66,6 \% para 90,0\%, o acompanhamento de vegetais de $69,2 \%$ para $85,7 \%$, a fruta de $66,6 \%$ para $84,6 \%$, o peixe de 50,0 \% para 83,3 \% e a água de 26,6 \% para $56,2 \%$. A solicitação de alimentos de colegas foi menos notória, apesar de ainda se verificar, especialmente nos momentos mais iniciais sinais dessa intencionalidade. 
Da capacitação desenvolvida com o sujeito 3 verificaram-se alterações nos hábitos alimentares (Figura 3).

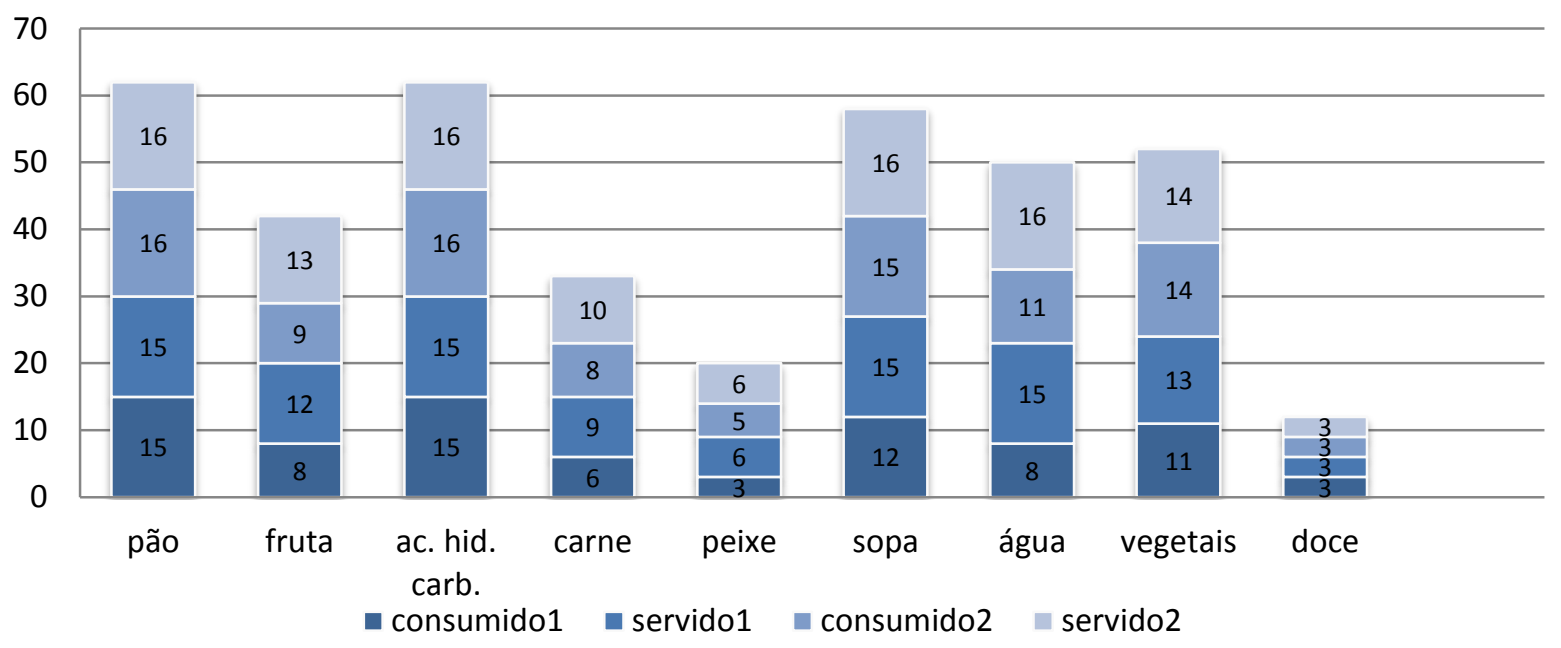

Figura 3: Comparação entre os alimentos consumidos e os alimentos servidos antes e após a capacitação do sujeito 3.

No segundo período de observação os dados revelam a manutenção da ingestão do pão, acompanhamento fornecedor de hidratos de carbono e do doce (100\%). Os vegetais com um registo inicial de $84,6 \%$ atingem $100 \%$ de consumo, a sopa de $80,0 \%$ passa a $93,7 \%$, o peixe de $50,0 \%$ para 83,3 \% e a água de $53,3 \%$ para $68,7 \%$. A ingestão aumentada de outros alimentos contribuiu para uma solicitação menos significativa de alimentos às colegas, embora ainda se manifestasse. O alerta para o aumento de peso e para alcançar uma silhueta mais volumosa parece ter contribuído para uma ingestão mais moderada de alimentos.

No segundo ciclo de observação, relativamente ao sujeito 4, os dados revelam (Figura 4) a manutenção da ingestão do pão, do acompanhamento fornecedor de hidratos de carbono e do doce (100\%).

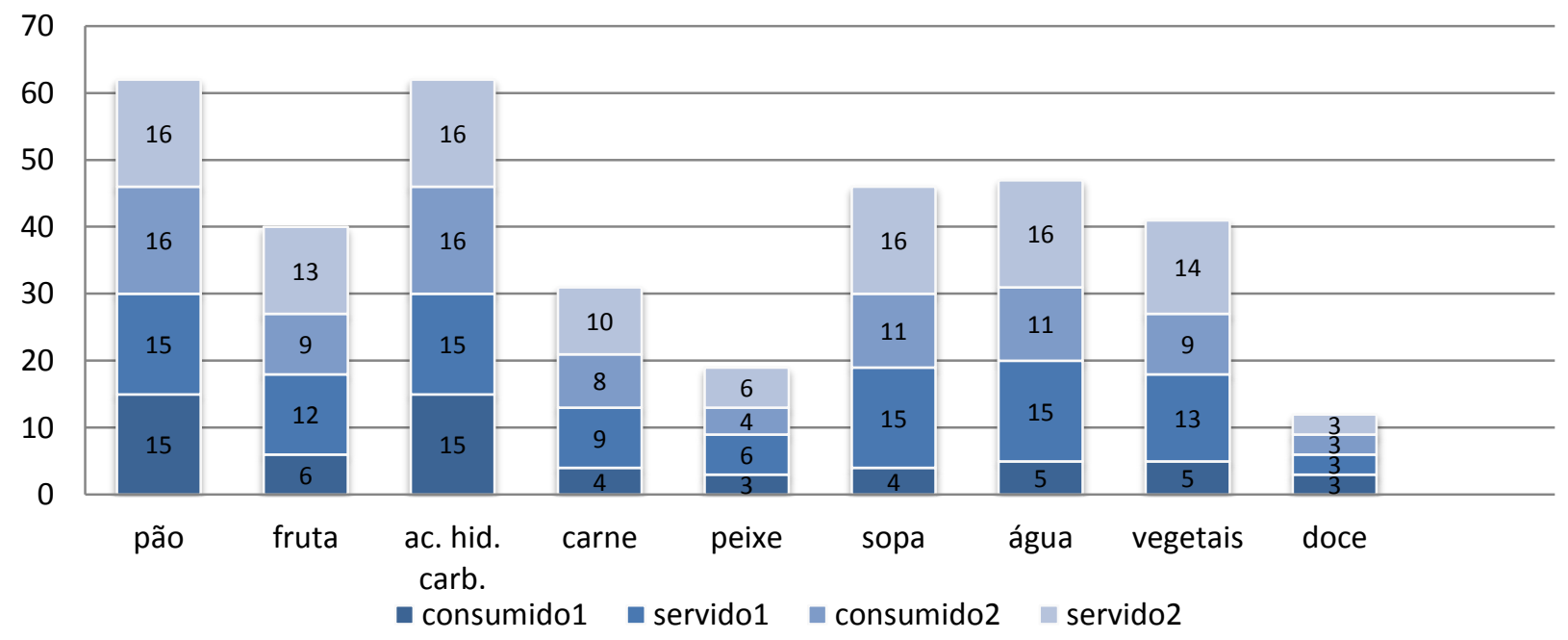

Figura 4: Comparação entre os alimentos consumidos e os alimentos servidos antes e após a capacitação do sujeito 4. 
A carne aumentou de $44,4 \%$ para $80,0 \%$, o peixe e a fruta passaram de $50,0 \%$ para 66,6 $\%$ e $53,8 \%$ respetivamente. O acompanhamento de vegetais passou de $38,4 \%$ para $64,2 \%$ e a sopa e a água atingiram o valor de $68,7 \%$, tendo registado no primeiro ciclo de observação 26,6 $\%$ e 33,3 \%, respetivamente. A ingestão aumentada de outros alimentos parece ter contribuído para uma solicitação menos frequente de alimentos às colegas, tendo ainda acontecido esta solicitação. $O$ alerta para o aumento de peso e para alcançar uma silhueta mais volumosa parece ter contribuído para uma ingestão mais moderada de alimentos.

Relativamente ao sujeito 5, os registos do segundo ciclo de observações (Figura 5) revela a manutenção da ingestão integral do pão, acompanhamento fornecedor de hidratos de carbono e do doce. A ingestão da sopa decai de $100 \%$ para $75,0 \%$. A carne e o peixe passam de $66,6 \%$ para $90,0 \%$ e $83,3 \%$, respetivamente. O acompanhamento de vegetais aumenta de $46,1 \%$ para 71,4 $\%$, a fruta de $41,6 \%$ para $76,9 \%$ e a água de $40,0 \%$ para $75,0 \%$.

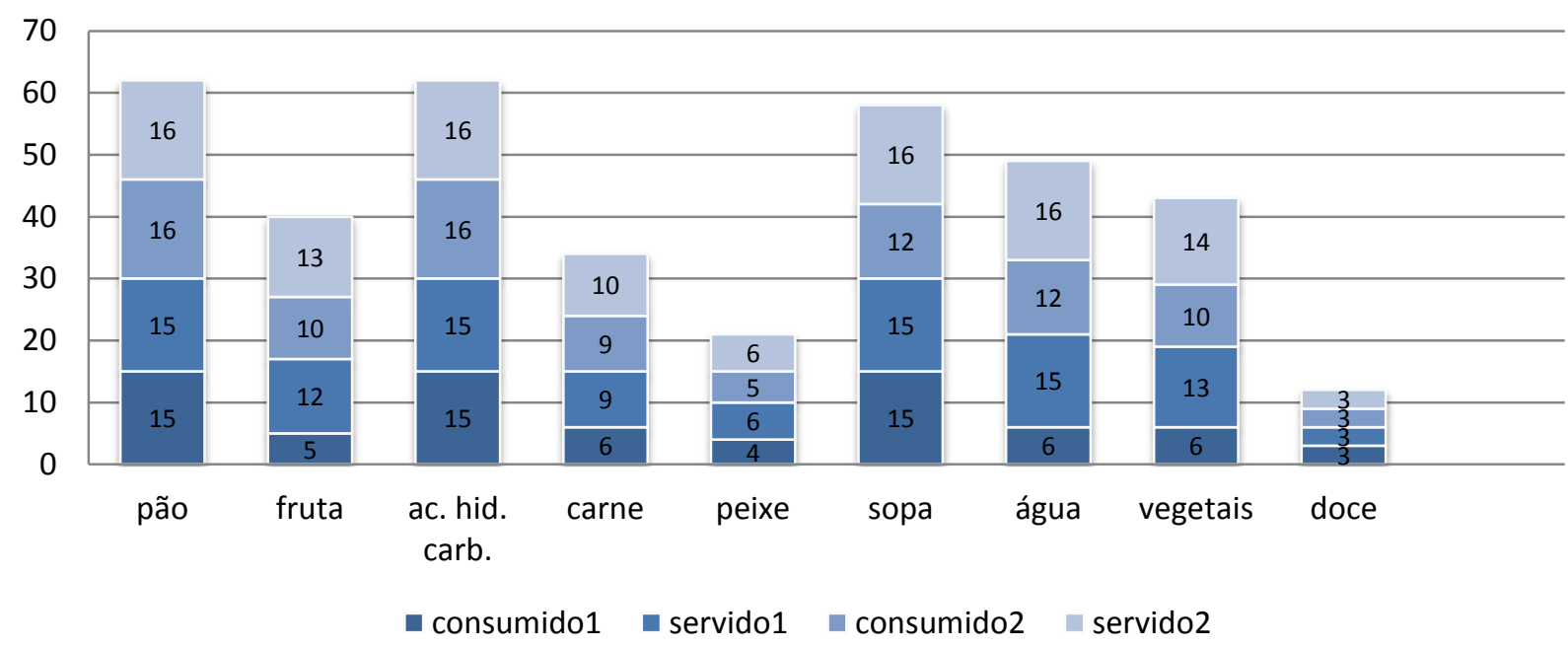

Figura 5: Comparação entre os alimentos consumidos e os alimentos servidos antes e após a capacitação do sujeito 5.

Os dados relativos ao segundo ciclo observacional do sujeito 6 apresentam-se na Figura 6.

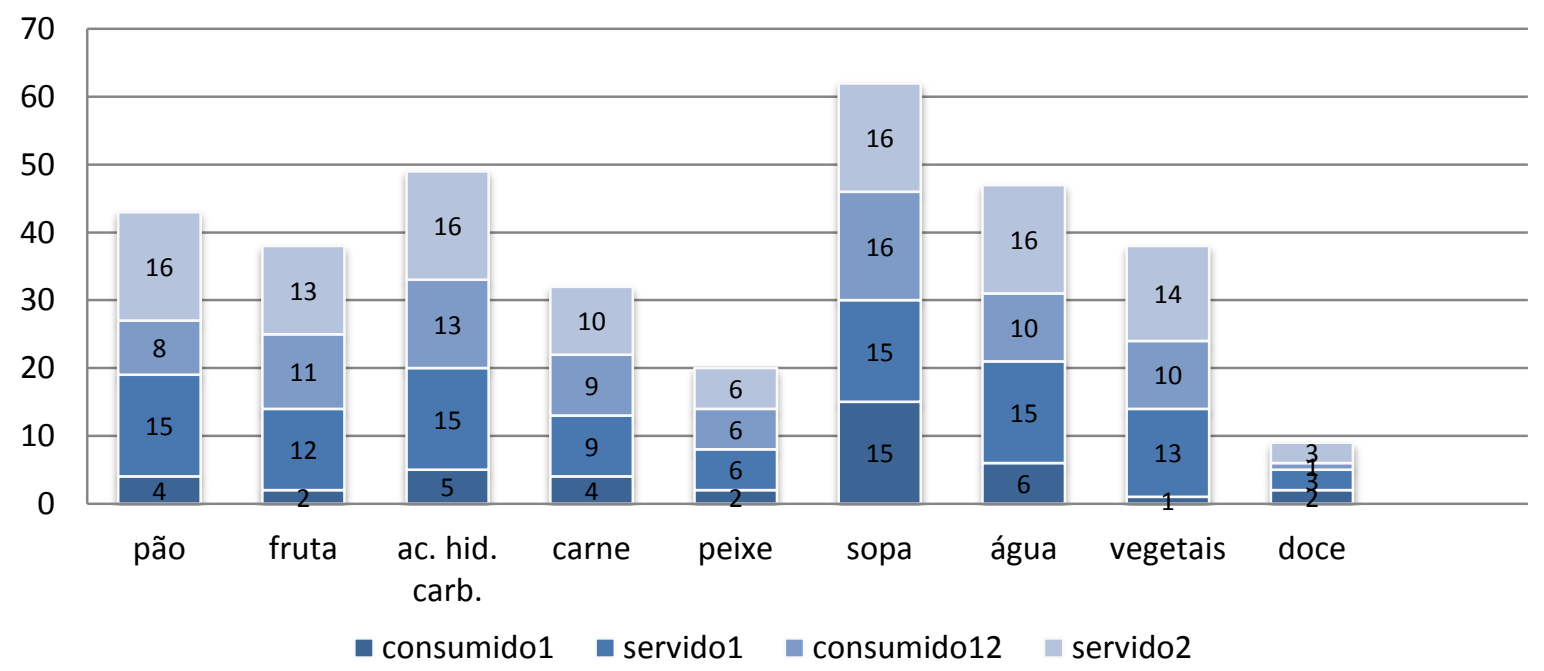

Figura 6: Comparação entre os alimentos consumidos e os alimentos servidos antes e após a capacitação do sujeito 6. 
Mantem-se o consumo total da sopa. A ingestão de vegetais regista um incremento de 7,6 $\%$ para $71,4 \%$, a de peixe de $33,3 \%$ para $100 \%$, a carne de $44,4 \%$ para $90,0 \%$, a da fruta de 16,6 $\%$ para $84,6 \%$, a do acompanhamento de glícidos de $33,3 \%$ para $81,2 \%$, o pão de $26,6 \%$ para $50,0 \%$, a água de $40,0 \%$ para $62,5 \%$ e o doce decresce de $66,6 \%$ para $33,3 \%$. A aluna apresentou uma alteração expressiva na frequência de consumo dos componentes da ementa do almoço. Destaca-se alguns aumentos de consumo, sendo o mais considerável o do acompanhamento de vegetais $(63,7 \%)$, acompanhados de um decréscimo no consumo de doce.

O seu comportamento relativamente à dispensa de alimentos a colegas foi menos frequente. $O$ alerta para a necessidade de ganhar peso para que ficasse mais bonita e o reforço verbal elogioso durante a refeição, no momento em que a ingestão dos alimentos ia decorrendo, parece ter contribuído para a mudança de hábitos alimentares verificados.

\section{DISCUSSÃO DOS RESULTADOS}

Esta investigação pretendeu conhecer quais os efeitos de um programa de capacitação aplicado às alunas com DI na alteração das suas práticas alimentares, em ambiente escolar. Associado a esta alteração, atuou-se também sobre as práticas de higiene e de normas de comportamento à mesa (embora neste momento não se dê conta desses resultados). Tendo em conta os objetivos definidos pretendia-se que cada sujeito desenvolvesse atitudes positivas perante os alimentos saudáveis e a aceitação de uma alimentação saudável como promotora de saúde.

Apresentam-se, de seguida, as conclusões por sujeito, em consequência do estudo se apresentar de casos individuais, com NEE, sem qualquer intenção de estabelecer comparações entre os mesmos.

O sujeito 1 representa uma aluna com perturbações do espetro do autismo. Esta perturbação desenvolvimental afeta a sua capacidade de comunicação, de jogar e interagir com os outros sendo também típicas a obsessão e a resistência a mudanças. Relativamente ao padrão alimentar, a aluna apresentava um restrito leque de preferências e rejeitava algumas texturas, 0 que tende a coincidir com o postulado por Ability Path.org (ca. 2012). Esta aluna situa-se num percentil de baixo peso. Os resultados da capacitação apontam para uma mudança comportamental. O comportamento alimentar é passivo de alterações mesmo em sujeitos em que existem hábitos instalados e com forte enraizamento. Não foi alcançada uma mudança plena apesar dos ganhos verificados. As significativas alterações registadas prendem-se com o consumo de água e de acompanhamento de vegetais, repetindo que beneficiavam a sua saúde. As fontes de proteínas não foram diariamente ingeridas. Os laços estabelecidos, a confiança e a apresentação de exemplos de mudança assim como o comportamento do grupo parecem-nos tender a contribuir para as alterações verificadas.

No que se refere ao sujeito 2, uma aluna com DM grave, apresentava excesso de peso. A aluna alimentava-se, em alguns episódios, de forma excessiva, recolhendo alimentos que outras colegas não ingeriam. O seu comportamento alimentar também denotou alterações. Demonstrou mudança e revelou maior controlo na ingestão de alimentos que ingeria em quantidade desajustada. Relativamente ao seu gosto por doces testemunhámos a sua 
manutenção. Todavia, o seu comportamento revelou-se mais controlado e ingeriu-os apenas na quantidade que lhe eram disponibilizados como sobremesa doce e em ocasiões festivas. Manteve a ingestão plena da sopa e do acompanhamento de hidratos de carbono. Os laços estabelecidos, a confiança e a apresentação de exemplos de mudança assim como o comportamento do grupo nos parecem tender a contribuir para as alterações verificadas.

O sujeito 3 apresenta IMC normal para a sua idade. A aluna ingeria a totalidade de diversos alimentos. Consumia pão, acompanhamento fornecedor de glícidos e em alguns casos doces, que solicitava às colegas que pretendiam não consumir os referidos alimentos. Passou, após a sequência didática, a apresentar um maior consumo de alimentos que não ingeria totalmente e manifestou menos vontade de ingerir suplementarmente pão e acompanhamento fornecedor de glícidos. O facto de esta aluna revelar muito gosto por cuidar da sua imagem, nomeadamente apreciar peças de vestuário, penteados e produtos de beleza, assim como desfilar imaginando-se numa passerelle, parece ter sido determinante para revelar a vontade de não aumentar o seu peso. O elogio frequente ao seu aspeto corporal por parte dos investigadores terá contribuído para a alteração do seu comportamento alimentar. Todavia, continuou a solicitar doces a diversos elementos da comunidade escolar, que sempre acederam aos seus pedidos de guloseimas, fora de ocasiões festivas, sem revelarem preocupações com o seu regime alimentar.

O sujeito 4 apresentava IMC normal. Os seus hábitos alimentares privilegiavam a ingestão total de pão, acompanhamento de hidratos de carbono e de doce. Revelou-se o aumento dos demais constituintes da refeição no período que decorreu após a intervenção de capacitação. Também se observou uma menor solicitação de alimentos às colegas. $O$ alerta que recolheu das sessões onde se frisou a possibilidade de aumentar o volume corporal, adoecer e ficar deselegante pareceram ter contribuído para uma ingestão alimentar mais próxima da recomendada. Para tais alterações parece ter contribuído a sequência pedagógica implementada.

O sujeito 5 apresentava um valor de IMC normal. A aluna revelou alteração do seu comportamento alimentar aproximando-se de um padrão saudável. $\mathrm{O}$ elogio à melhoria dos seus comportamentos e práticas alimentares também parecem contribuir para as novas práticas adotadas.

O sujeito 6 situa-se num percentil de baixo peso. Apresentava práticas alimentares desequilibradas com ingestão reduzida de muitos dos constituintes da refeição. Após a sequência didática de capacitação, as práticas alimentares alteraram-se significativamente. A refeição aproximou-se da recomendada. O gosto pela dança e por cuidar do seu aspeto, associado aos elogios e à motivação transmitida pelos investigadores pareceram contribuir para a alteração do comportamento alimentar.

A ajuda oferecida no decurso da refeição tende a resultar em ganhos nas práticas alimentares que não se associam a problemas de saúde, o que confluí com dados revelados pela UNICEF (2013). Momentos compulsivos de consumo de alimentos, apetite insaciável e desequilíbrio na sensação de apetite (BENTO, 2008) foram vivenciados neste estudo, não se revelando fácil a intervenção dos investigadores nesses momentos. Porém, nas sessões didáticas a referência a alguns dos referidos momentos foi promotora de momentos de reflexão por parte de alguns dos sujeitos e, coincidindo com Bento (2008), a alteração dos hábitos alimentares parece ter contribuído para o controlo do apetite. A oferta de doces ou a anuência aos pedidos 
das alunas entre a comunidade escolar diminuiu, constituindo-se uma prática compensatória das problemáticas das alunas.

A investigação realizada atende ao postulado por Correia (2003) defendendo que à escola inclusiva se impõe o respeito por todos os alunos estimulando-os para a aprendizagem até ao limite das suas capacidades, respeitando sempre as necessidades de cada aluno de forma a integrá-los e incluí-los no contexto escolar.

\section{CONCLUSÕES}

O estudo que realizámos, permanentemente norteado pela questão-pivô traçada, permitiu desenvolver nas crianças com DI atitudes positivas face a todos os alimentos saudáveis e estimular a aceitação de uma alimentação saudável e diversificada como forma de promoção da saúde. Para tal sucesso, foram diagnosticados os hábitos alimentares manifestados pelas alunas em ambiente escolar, mediante observação, associados ao seu comportamento social em ambiente de refeitório escolar. Tal análise conduziu à conceção e execução de um programa de capacitação, dirigido a cada caso de DI específico, tendo produzido efeitos imediatos nos hábitos alimentares dos sujeitos envolvidos.

Para os sujeitos estudados os fatores ambientais, em meio escolar, constituem-se como facilitadores elevados particularmente os conhecidos, pares, colegas e membros da comunidade, pessoas em posição de autoridade na escola e o trabalho em parceria desenvolvido por todos os profissionais, com base na CIF e de acordo com registos nos seus PEl. Ao decorrer no espaço escolar, envolvendo diversos atores, fatores ambientais facilitadores, parece tender para maior motivação dos sujeitos às atividades desenvolvidas na sequência didática.

Tendo por base que uma alimentação saudável durante a infância e adolescência, diminui o risco de problemas ao nível da saúde relacionados com a nutrição e os hábitos alimentares criados nestes períodos apresentam-se duradouros e com a possibilidade de se manterem no futuro (ARANCETA et al., 2008; CURRIE et al., 2012).

Oferece-nos concluir da pertinência da implementação de sequências didáticas que visem a capacitação de crianças com DI para práticas alimentares saudáveis em consequência das alterações observadas neste estudo. Não existe, todavia, qualquer garantia da mudança de atitudes e, consequentemente, a conservação temporal dos novos comportamentos. Os hábitos instalados estão enraizados o que nos leva a crer que nestes sujeitos em particular, o reforço e o estímulo aos novos comportamentos deve ser continuado, de modo a torná-los adquiridos, sentidos como naturais, desestruturando os comportamentos anteriores. Esse caminho, agora colocado em evidência, pode ser assegurado pelos professores e assistentes operacionais que têm a missão do apoio a estas crianças, conduzindo-as a uma alimentação saudável, que lhes permita nesse domínio um acesso a um nível de qualidade de vida igual ao dos demais colegas.

\section{REFERÊNCIAS BIBLIOGRÁFICAS}

1. ABILITY PATH.ORG. Finding Balance Obesity and Children with Special Needs, ca. 2012. Disponível em http://www.abilitypath.org/health-daily-care/health/growth-and-nutrition/ articles/obesity/pdfs/obesity-report.pdf. Acesso: 2 mar. 2014. 
2. ADA - American Dietetic Association. Nutrition, aging, and the continuum of care. Journal of the American Dietetic Association, n. 96, 1048-1052, 1996.

3. AINSCOW, M.; FERREIRA, W. Compreendendo a educação inclusiva. Algumas reflexões sobre experiências internacionais. In: Rodrigues, D. (Org.). Perspectivas sobre a inclusão. Da educação à sociedade. Porto: Porto Editora, 2003, p. 103-116.

4. APD - Associação Portuguesa de Dietistas. Nutrição \& Saúde. A pirâmide alimentar, 2014. Disponível em Retirado em http://www.apdietistas.pt/nutricao-saude/alimentacao-nasaude/dieta-mediterranea?highlight=WyJwaXJcdTAwZTJtaWRIliwiYWxpbWVudGFyliwicGlyX HUwMGUybWIkZSBhbGItZW50YXIiXQ. Acesso em: 21 abr. 2014.

5. APN - Associação Portuguesa dos Nutricionistas. Healthy Eating Plate, 2012. Disponível em: http://www.apn.org.pt/scid/webApn/defaultArticleViewOne.asp?articlelD=479\&categorylD= 873. Acesso em: 28 mar. 2014.

6. ARANCETA, J. et al. El comedor escolar: situación actualy guia de recomendaciones. An Pediatr (Barc), v. 69, n. 1, 72-88, 2008.

7. BAPTISTA, J. Introdução às Ciências da Educação: Temas e problemas da educação inclusiva. Lisboa: Universidade Católica Portuguesa, 2011.

8. BARDIN, L. Análise de conteúdo. Lisboa: Edições70, 1994.

9. BAUTISTA, R. Uma escola para todos: A integração escolar. In: Bautista, R. (Coord.). Necessidades Educativas Especiais. Lisboa: Dinalivro, 1997, p. 21-35.

10. BÉNARD DA COSTA, A. A Escola Inclusiva: Do conceito à prática. Inovação, v. 1, n. 1-2, p. 5765, 2005.

11. Bento, A. Alimentação saudável na Deficiência Intelectual. Revista Diversidades, v. 6, n. 22, p. 20-24, 2008. Disponível em http://www.madeira-edu.pt/Portals/7/pdf/revista_diversidades/ revistadiversidades_22.pdf. Acesso em: 31 mar. 2014.

12. BERENSON, G. et al. Rationale to study the early natural history of heart disease: the Bogalusa Heart Study. American Journal Medical Science, v. 310, n. Suppl 1, p. S22-S28, 1995.

13. BEST, J. Cómo investigar en educación. Madrid: Ediciones Morata, 1982.

14. BURKART, J.; FOX, R.; ROTATON, A. Obesity of mentally retarded individuals: Prevalence, characteristics and intervention. American Journal of Mental Deficiency, n. 90, p. 303-312, 1985.

15. CANDEIAS, V. et al. Princípios para uma Alimentação Saudável. Lisboa: Direção-Geral da Saúde, 2005.

16. CARTWRIGHT, D. L'Analyse du Matériel Qualitatif. In: Festinguer, L.; Katz. D. (Eds.), Les Méthodes de Recherche dans les Sciences Sociales (Tomo 2). Paris: Presses Universitaires de France, 1974,p. 481-538.

17. CIF-CJ - Classificação Internacional da Funcionalidade Incapacidade e Saúde: versão crianças e jovens. Actividades de participação fatores ambientais. Versão Experimental traduzida e adaptada, com base na CIF (2003) e ICF-CY (no prelo). Porto: Centro de Psicologia do Desenvolvimento e Educação da Criança. Faculdade de Psicologia e de Ciências da Educação da Universidade do Porto, s.d. Disponível em: www.dgidc.min-edu.pt/educacaoespecial/ 
data/ensinoespecial/cif_cj.pdf. Acesso em: 21 out. 2013.

18. CORREIA, L. Alunos com necessidades educativas especiais nas classes regulares. Porto: Porto Editora, 1999.

19. CORREIA, L. Inclusão e necessidades educativas especiais: Um guia para educadores e professores. Porto: Porto Editora, 2003.

20. CORREIA, M. A observação participante enquanto técnica de investigação. Pensar Enfermagem, v. 13, n. 2, p. 30-36, 2009.

21. CURRIE, C. et al. Social determinants of health and well-being among young people. Health Behaviour in School-aged Children (HBSC) study: international report from the 2009/2010 survey. Copenhagen: WHO Regional Office for Europe, 2012.

22. DGE - Direção-Geral da Educação. Alimentação e atividade física, 2013. Disponível em http://www.dge.mec.pt/educacaosaude/index.php?s=directorio\&pid=1. Acesso em: 2 nov. 2013.

23. DGS - Direção-Geral da Saúde. Programa nacional promoção alimentar saudável. Realidade portuguesa, ca. 2012. Disponível em http://www.plataformacontraaobesidade.dgs.pt/ PresentationLayer/conteudo. aspx?menuid=115\&exmenuid=115\&SelMenuld=115. Acesso em: 2 nov 2013.

24. GREENWOOD, J.; STANFORD, J. Preventing or improving obesity by addressing specific eating patterns. JABFM, v. 21, p. 135-140, 2008.

25. HUBERMAN, M.; MILES, M. Data management and analysis methods. In: Norman, D.; Lincoln, Y. (Eds.). Handbook of qualitative research. London: Sage Publications, 1994, p. 769-802.

26. INE - INSTITUTO NACIONAL DE ESTATÍSTICA. Disponível em http://www.ine.pt/xportal/ xmain?xpid=INE\&xpgid=ine_indicadores\&indOcorrCod=0005889\&contexto=pi\&selTab=tab0. Acesso: 29 jan. 2015.

27. INTERNATIONAL UNION HEALTH PROMOTION AND EDUCATION. The IUHPE at a Glance (ca. 2014). Disponível em http://www.iuhpe.org/index.php/en/._Acesso: 18 abr. 2014.

28. KANN, L. et al. Youth risk behavior surveillance. Journal of School Health, v. 66, n. 377, 1996.

29. LIMA-RODRIGUES, L. (Coord.). Percursos de Educação Inclusiva em Portugal: dez estudos de caso. Lisboa: Universidade Técnica de Lisboa, 2007.

30. LINCOLN, S.; GUBA, E. Naturalistic inquiry. Beverly Hills: Sage, 1985.

31. MAXWELL, J. Qualitative Research Design: an interative approach. Thousand: Sage, 1996.

32. NICKLAS, T. et al. Eating patterns, dietary quality and obesity. Journal of American College of Nutrition, v. 20, n. 6, p. 599-608, 2001.

33. NIELSEN, L. Necessidades Educativas Especiais na Sala de Aulas: Um guia para professores. Porto: Porto Editora, 1999.

34. NUNES, E.; BREDA, J. Manual para uma alimentação saudável em jardins-de-infância. Lisboa: Direção-Geral da Saúde, 2001.

35. OMS - Organização mundial da Saúde. CIF - Classificação Internacional de Funcionalidade, Incapacidade e Saúde. Lisboa: Ministério da Saúde, 2004.

36. PERES, E. (1998). Educação alimentar - Vale a pena? Revista de Nutrição Portuguesa, vol. 1-2, 
n. 2, p. 43-54, 1998.

37. ROBINSON, T. et al. Is parental control over children's eating associated with childhood obesity? Results from a population-based sample of third graders. Obesity research, v. 9, n. 5, p. 306-312, 2001.

38. SANCHES, I.; TEODORO, A. Da integração à inclusão escolar: cruzando perspectivas e conceitos. Revista Lusófona de Educação, n. 8, p. 63-83, 2006. Disponível em: http://www.scielo. oces.mctes.pt/pdf/rle/n8/n8a05.pdf. Acesso: 3 dez. 2014.

39. SANTOS, J. A saúde pela alimentação. Porto: Avis, 1983.

40. SOUSA, A. Investigação em Educação. Lisboa: Livros Horizonte, 2005.

41. STEWART, L.; BEANGE, H.; MACKERRAS, D. A survey of dietary problems of adults with learning disabilities in the community. Mental Handicap Research, n. 7, p. 41-50, 1994

42. UNESCO - United Nations Education, Scientific and Cultural Organization. Declaração Mundial sobre Educação para Todos: Satisfação das necessidades básicas de aprendizagem, 1990. Disponível em: http://unesdoc.unesco.org/images/0008/000862/086291por.pdf. Acesso: 15 jan. 2014.

43. UNESCO - United Nations Education, Scientific and Cultural Organization. Declaração de Salamanca sobre princípios, política e práticas na área das necessidades educativas especiais, 1994. Disponível em: http://unesdoc.unesco.org/images/0013/001393/139394por.pdf. Acesso em: 20 jan. 2015.

44. UNICEF - United Nations Children's Fund. A convenção sobre os direitos da criança, 1989. Disponível em http://www.unicef.org/sowc2013/files/SWCR2013_ENG_Lo_res_24_Apr_2013 .pdf. Acesso em: 20 mar. 2014.

45. UNICEF - United Nations Children's Fund. The State of the World's Children 2013. Children with disabilities, 2013. Disponível em http://www.unicef.org/sowc2013/files/SWCR2013_ENG_Lo_res_24_Apr_2013.pdf. Acesso em: 20 mar. 2014.

46. VIANA, V. Psicologia, saúde e nutrição: Contributo para o estudo do comportamento alimentar. Análise Psicológica, n. 4, p. 611-624, 2002.

47. WHO - World Health Organization (2008). Controlling the global obesity epidemic. Disponível em http://www.who.int/nutrition/topics/obesity/en//index.html. Acesso em: 21 fev 2014.

\section{Legislação Consultada}

Lei Constitucional no $1 / 2005$, de 12 de agosto

Lei $n=35 / 2014$, de 20 de junho

Decreto-Lei no 3/2008, de 7 de janeiro

Decreto-Lei no 319/1991, de 23 de agosto

Despacho no 2506/2007, de 20 de fevereiro 